\title{
TERT promoter mutations and telomere length in adult malignant gliomas and recurrences
}

\author{
Barbara Heidenreich ${ }^{1}$, P. Sivaramakrishna Rachakonda ${ }^{1}$, Ismail Hosen ${ }^{1}$, \\ Florian Volz ${ }^{2}$, Kari Hemminki ${ }^{1,3}$, Astrid Weyerbrock², Rajiv Kumar ${ }^{1}$ \\ ${ }^{1}$ Division of Molecular Genetic Epidemiology, German Cancer Research Center, Heidelberg 69120, Germany \\ ${ }^{2}$ Department of Neurosurgery, University Medical Center Freiburg, Freiburg 79106, Germany \\ ${ }^{3}$ Center for Primary Health Care Research, Lund University, Malmö, Lund 22100, Sweden
}

Correspondence to:

Barbara Heidenreich, e-mail: b.heidenreich@dkfz.de

Rajiv Kumar, e-mail: r.kumar@dkfz.de

Keywords: Gliomas, TERT promoter, IDH, telomere length, TERT expression

Received: January 07, $2015 \quad$ Accepted: February 09, $2015 \quad$ Published: March 12, 2015

\section{ABSTRACT}

In this report on $\mathbf{3 0 3}$ gliomas we show the highest frequency of TERT promoter mutations in gliobastomas $(80 \%)$ followed by oligodendrogliomas $(70 \%)$ and astrocytomas (39\%). We observed positive association between TERT promoter and $I D H$ mutations in oligodendroglial tumors ( $O R=26.3 ; 95 \% C I 2.5-250.2)$ and inverse association in primary glioblastomas ( $O R=0.13 ; 95 \% \mathrm{CI} 0.03-0.58)$. Tumors with TERT promoter mutations compared to those without showed increased TERT transcription; we also showed difference in the transcription levels due to the two main mutations. Tumors with TERT promoter mutations had shorter telomeres than those without. The patients with only TERT promoter mutations showed worst survival (median survival 14.6 months) and patients with both IDH and TERT promoter mutations showed best survival ( 246.5 months). In patients with astrocytoma, the TERT promoter mutations only associated with poor survival $(P<0.0001)$; IDH mutations and 1p/19q deletions associated with increased survival $(P=0.0004)$. TERT promoter mutations in low grade gliomas associated with reduced progression free survival (HR 10.2; 95\% CI 1.9 - 55.9). While our data affirm the role of TERT promoter mutations in glial tumors, effects on transcription and telomere length emphasise the importance of telomere biology in disease genesis and outcome.

\section{INTRODUCTION}

Gliomas are the most common primary malignant brain tumors in adults that mainly arise in glial tissue of the brain. Those tumors are either astrocytic, oligodendrocytic or a mixture of the two cell types and are typically categorized according to the International Classification of Diseases - Oncology, version 3 (ICD-O-3) and World Health Organization (WHO) grade $[1,2]$. The most common gliomas are glioblastomas, comprising the two sub-types primary and secondary glioblastoma. The sub-types follow different modes of progression and show distinct genetic alterations [1, 3-5]. The majority is constituted by primary glioblastomas and those tumors develop quickly. Most of the patients present symptoms less than six months prior to diagnosis [3]. As a consequence, glioblastomas exhibit a poor prognosis with a 5 -year relative survival of $\sim 5 \%[1]$.

Challenging histopathological features of glial tumors and new possibilities in treatment add to the need of genetic markers with prognostic as well as predictive potential [6-10]. Mutations in Isocitrate dehydrogenase 1 (IDH1) and - less common - Isocitrate dehydrogenase 2 (IDH2) are examples for genetic alterations with prognostic value and potential as novel therapeutic targets $[9,11]$. As such, $I D H$ $(I D H 1$ and $I D H 2)$ mutations are associated with prolonged progression-free survival and seem to indicate patients that might benefit from chemoradiotherapy [12]. Those mutations are common within gliomas that follow astrocytic progression (astrocytomas, oligoastrocytomas and secondary 
glioblastomas) but are rare in primary glioblastomas [13, 14]. Co-deletions of chromosome $1 p$ and $19 q$ have also been demonstrated to associate with better survival rates and furthermore correlate with $I D H$ mutations, representing a typical feature of the oligodendroglial subtype [14, 15].

Reports on mutations within the core promoter of the telomerase reverse transcriptase (TERT) gene in different cancers have consistently shown occurrence at highest frequencies in adult gliomas [16-21]. TERT encodes the ratelimiting catalytic subunit of telomerase, which is involved in de novo addition of telomere repeats at chromosomal ends. The discovery of the TERT promoter mutations provides a possibility for (i) gaining insight into mechanistic questions in glioma development and (ii) a new biomarker and eventual therapeutic target [22]. The TERT promoter mutations exert influence through increased expression due to creation of new binding motifs for Ets/TCF transcription factors [23]. Recent reports indicate a clear subtype-specific distribution of the TERT promoter mutation in different gliomas, which in combination with $I D H$ mutations allows classification according to their histological subgroups [24, 25].

In the present study, we investigated and show the occurrence and correlations between alterations at $C D K N 2 A / B, 1 \mathrm{p} / 19 \mathrm{q}, I D H$ and the TERT promoter mutations in different histological sub-types of gliomas and their effect on patient survival. We also show that the presence of TERT promoter mutations influences telomere length and affect the gene expression.

\section{RESULTS}

\section{Patient characteristics}

A total of 303 gliomas and 22 recurrences from patients treated at the Department of Neurosurgery of the
University Medical Center Freiburg were investigated. The 303 primary tumors comprised of 56 astrocytomas, 55 oligoastrocytomas, 27 oligodendrogliomas and 165 primary or de novo glioblastomas (Table 1). The patient group included 111 women and 192 men with a mean age of $53 \pm 17$ years (median 55; range: $8-85$ years; Table 2; Supplementary Table 1).

\section{TERT promoter mutations}

Overall TERT promoter mutations were present in 199 of $303(66 \%)$ gliomas. The $-124 \mathrm{C}>\mathrm{T}$ mutation was present in 147 tumors (74\%), whereas $-146 \mathrm{C}>\mathrm{T}$ was found in 51 cases $(26 \%)$ and one tumor carried the $-124 \_125 \mathrm{CC}>\mathrm{TT}$ tandem mutation. Primary glioblastomas had the highest frequency of TERT promoter mutations $(132 / 165 ; 80 \%)$ followed by oligodendrogliomas $(19 / 27$; $70 \%$ ); astrocytomas showed the lowest frequency, with 22 out of $56(39 \%)$ samples showing mutations (Table 1). A difference in the frequency of mutations in tumors from women and men was not statistically significant. TERT promoter mutations were more frequent in patients older than 55 years of age at diagnosis $(\mathrm{OR}=$ 5.07; 95\% CI $2.99-8.60 ; P<0.0001)$. Also, TERT promoter mutations were found associated with high grade (grade III + IV) tumors when compared to lower grade (grade II) lesions $(\mathrm{OR}=3.05 ; 95 \%$ CI $1.79-5.19 ; P<0.0001$; Table 2).

\section{$T E R T$ promoter mutations and alterations in other genes}

Besides TERT promoter mutations, we investigated alterations at $C D K N 2 A / B, I D H 1, I D H 2$ and chromosome arms $1 \mathrm{p}$ and $19 \mathrm{q} . I D H 1$ or $I D H 2$ mutations (' $I D H$ mutations') were present in 100 of 303 (33\%) glioma tumors (Table 1).

\section{Table 1: Frequencies of alterations at the TERT promoter, $I D H 1 / 2,9 \mathrm{p} 21$ and $1 \mathrm{p} / 19 \mathrm{q}$ in different glioma subtypes}

\begin{tabular}{|c|c|c|c|c|c|}
\hline & All & Astrocytomas & Oligoastrocytomas & Oligodendrogliomas & $\begin{array}{c}\text { Primary } \\
\text { Glioblastomas }\end{array}$ \\
\hline & $n=303$ & $n=56$ & $n=55$ & $n=27$ & $n=165$ \\
\hline $\begin{array}{l}T E R T \text { promoter } \\
\text { mutations }\end{array}$ & $199 / 303(65.7 \%)$ & $22 / 56(39.3 \%)$ & $26 / 55(47.3 \%)$ & $19 / 27(70.4 \%)$ & $\begin{array}{l}132 / 165 \\
(80.0 \%)\end{array}$ \\
\hline IDH1/2 mutations & $100 / 303(33.0 \%)$ & $37 / 56(66.1 \%)$ & $39 / 55(71.0 \%)$ & $16 / 27(59.3 \%)$ & $8 / 165(4.9 \%)$ \\
\hline 9p21 deletions & $119 / 257(46.3 \%)$ & $17 / 47(36.2 \%)$ & $13 / 47(27.7 \%)$ & $9 / 25(36.0 \%)$ & $\begin{array}{c}80 / 138 \\
(58.0 \%)\end{array}$ \\
\hline deletions at 1p/19q & $74 / 259(28.6 \%)$ & $15 / 49(30.6 \%)$ & $24 / 47(51.1 \%)$ & $14 / 25(56.0 \%)$ & $\begin{array}{c}21 / 138 \\
(15.2 \%)\end{array}$ \\
\hline deletions at $1 \mathrm{p}$ & $12 / 259(4.6 \%)$ & $3 / 49(6.1 \%)$ & $0 / 47(0 \%)$ & $0 / 25(0 \%)$ & $9 / 138(6.5 \%)$ \\
\hline deletions at $19 q$ & $15 / 259(5.8 \%)$ & $2 / 49(4.1 \%)$ & $5 / 47(10.6 \%)$ & $0 / 25(0 \%)$ & $8 / 138(5.8 \%)$ \\
\hline $1 \mathrm{p} / 19 \mathrm{q}$ co-deletion & $47 / 259(18.1 \%)$ & $10 / 49(20.4 \%)$ & $19 / 47(40.4 \%)$ & $14 / 25(56 \%)$ & $4 / 138(2.9 \%)$ \\
\hline
\end{tabular}


Table 2: Distribution of $T E R T$ promoter mutations and association with genetic alterations in gliomas

\begin{tabular}{|c|c|c|c|c|}
\hline & \multirow[t]{2}{*}{ All $n=303$} & \multicolumn{2}{|c|}{ TERT promoter } & \\
\hline & & wt & mut & \\
\hline $\begin{array}{l}\text { Gender } \\
\text { male } \\
\text { female }\end{array}$ & $\begin{array}{l}192 \\
111 \\
\end{array}$ & $\begin{array}{l}72 \\
32 \\
\end{array}$ & $\begin{array}{c}120 \\
79 \\
\end{array}$ & $\mathrm{OR}=1.48 ; 95 \%$ CI $0.8-2.45 ; P=0.1$ \\
\hline $\begin{array}{l}\text { Age } \\
\quad \leq 55 \\
>55\end{array}$ & $\begin{array}{l}152 \\
151\end{array}$ & $\begin{array}{l}78 \\
26\end{array}$ & $\begin{array}{c}74 \\
125\end{array}$ & $\mathrm{OR}=5.07 ; 95 \%$ CI $2.99-8.60 ; \boldsymbol{P}<\mathbf{0 . 0 0 0 1}$ \\
\hline $\begin{array}{l}\text { Grade } \\
\text { low (II) } \\
\text { high (III + IV) } \\
\end{array}$ & $\begin{array}{c}78 \\
225 \\
\end{array}$ & $\begin{array}{l}42 \\
62 \\
\end{array}$ & $\begin{array}{c}36 \\
163 \\
\end{array}$ & $\mathrm{OR}=3.05 ; 95 \%$ CI $1.79-5.19 ; \boldsymbol{P}<\mathbf{0 . 0 0 0 1}$ \\
\hline $\begin{array}{l}\text { IDH } \\
\text { wildtype } \\
\text { mutation } \\
\end{array}$ & $\begin{array}{l}203 \\
100 \\
\end{array}$ & $\begin{array}{l}53 \\
51 \\
\end{array}$ & $\begin{array}{c}150 \\
49\end{array}$ & $\mathrm{OR}=0.34 ; 95 \%$ CI $0.21-0.56 ; \boldsymbol{P}<\mathbf{0 . 0 0 0 1}$ \\
\hline $\begin{array}{l}9 \mathrm{p} 21 \\
\text { wildtype } \\
\text { mutation } \\
\text { missing } \\
\end{array}$ & $\begin{array}{c}138 \\
119 \\
46\end{array}$ & $\begin{array}{l}60 \\
24\end{array}$ & $\begin{array}{l}78 \\
95\end{array}$ & $\mathrm{OR}=3.04 ; 95 \%$ CI $1.74-5.33 ; \boldsymbol{P}<\mathbf{0 . 0 0 0 1}$ \\
\hline $\begin{array}{l}\text { Deletions at } 1 \mathrm{p} \text { and/or } 19 \mathrm{q} \\
\text { wildtype } \\
\text { deletion } \\
\text { missing }\end{array}$ & $\begin{array}{c}185 \\
74 \\
44 \\
\end{array}$ & $\begin{array}{l}73 \\
12\end{array}$ & $\begin{array}{c}112 \\
62\end{array}$ & $\mathrm{OR}=3.37 ; 95 \%$ CI $1.70-6.68 ; \boldsymbol{P}=\mathbf{0 . 0 0 0 3}$ \\
\hline $\begin{array}{l}\text { 1p/19q codeletions } \\
\text { wildtype } \\
\text { codeletion } \\
\text { missing }\end{array}$ & $\begin{array}{c}214 \\
45 \\
44\end{array}$ & $\begin{array}{c}85 \\
0\end{array}$ & $\begin{array}{c}129 \\
45\end{array}$ & $\mathrm{OR}=1.35 ; 95 \%$ CI $1.24-1.47 ; \boldsymbol{P}<\mathbf{0 . 0 0 0 1}$ \\
\hline
\end{tabular}

$P$-values were derived from $\chi^{2}$-test and considered statistically significant if $<0.05$.

Bold font indicates statistical significance.

The c.395G > A (R132H) mutation in IDH1 was the most common one, present in 94 cases (94\%); two gliomas harbored the $I D H 1$ c.394C $>$ T mutation (R132H). IDH2 mutations were found in four tumors $(4 \%)$, with c.515G $>$ $\mathrm{A}(\mathrm{R} 172 \mathrm{~K})$ in three tumors and c. $515 \mathrm{G}>\mathrm{T}(\mathrm{R} 172 \mathrm{M})$ in one tumor. The highest frequency of $I D H$ mutations was detected in oligoastrocytomas $(39 / 55 ; 71 \%)$, followed by astrocytomas (37/56; 66\%) and oligodendrogliomas (16/27; 59\%) (Table 1).

Data on deletions at $1 \mathrm{p}$ and/or $19 \mathrm{q}$ were available for 259 gliomas. 74 tumors had deletions at chromosome arms $1 p$ and/or 19q, of which 47 were co-deletions at both loci. The highest frequency of $1 p / 19 q$ co-deletions was in oligodendrogliomas with $14 / 28(56 \%)$, followed by oligoastrocytomas 19/47 (40\%). The CDKN2C (p18 $8^{\mathrm{INK} 4 \mathrm{C}}$ ) locus at chromosome $1 \mathrm{p}$ showed focal deletions in nine gliomas, of which eight were primary glioblastomas and one was a grade II astrocytoma. Of these nine, six tumors were also deleted at the $C D K N 2 A / B$ and eight tumors carried TERT promoter mutations (Figure 1).

In the entire set of tumors mutations in $I D H$ and deletions at $1 p$ and/or $19 q$ were associated with an odds ratio (OR) of 9.97 (95\% CI $5.39-18.46 ; P<0.0001)$. TERT promoter mutations and deletions at $1 \mathrm{p} / 19 \mathrm{q}$ when present tended to occur together $(\mathrm{OR}=3.37 ; 95 \% \mathrm{CI} 1.70-6.68 ; P=$ 0.0003 ) (Table 2). In contrast, TERT promoter mutations and $I D H$ mutations were inversely correlated $(\mathrm{OR}=0.34 ; 95 \%$ CI $0.21-0.56 ; P<0.0001)$. However, in oligodendroglial tumors, TERT promoter and $I D H$ mutations occurred together ( $\mathrm{OR}=26.25 ; 95 \%$ CI $2.46-250.20 ; P=0.001)$. In primary glioblastomas the frequency of $I D H$ mutations was low $(8 / 165,5 \%)$ and showed an inverse correlation (OR $0.13 ; 95 \%$ CI $0.03-0.58 ; P=0.002$ ) with TERT promoter mutations $(132 / 165 ; 80 \%)$. In astrocytomas, where both, TERT promoter and $I D H$ mutations, were frequent, the OR of 0.60 suggested an inverse association; however this observation was not statistically significant (Supplementary Table 2).

The $C D K N 2 A / B$ locus was deleted in 119 of $257(46 \%)$ gliomas. The highest frequency of deletions was observed in primary glioblastomas $(80 / 138 ; 58 \%)$ (Table 1$)$. Association between loss of $C D K N 2 A / B$ and the TERT promoter mutations was statistically significant associated $(\mathrm{OR}=3.04$; 95\% CI 1.74 - 5.33, $P<0.0001$ ) (Supplementary Table 2). 


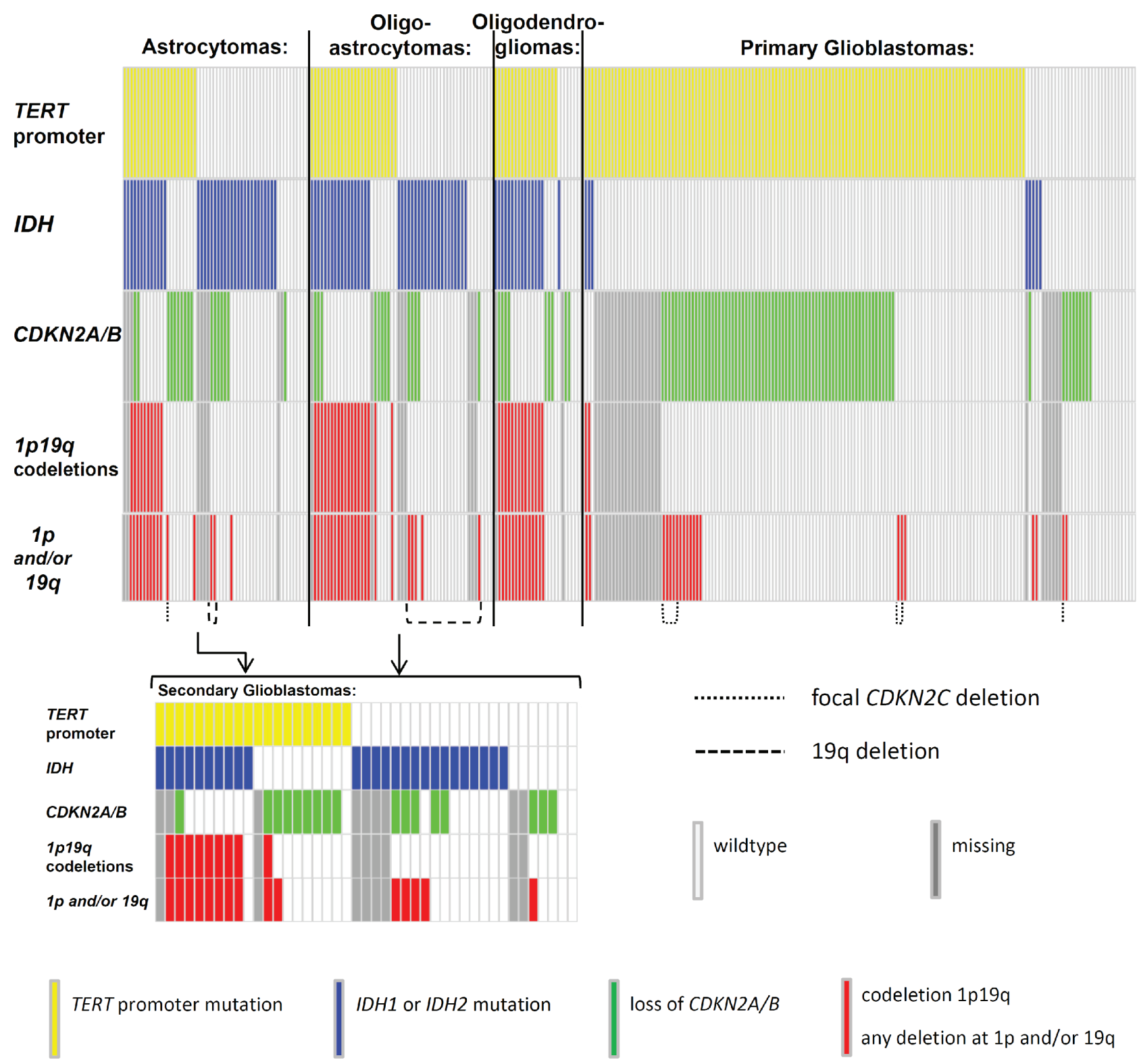

Figure 1: Distribution of mutations in gliomas. The distribution of mutations in the TERT promoter, IDH1 and IDH2 (IDH) and deletions at 9p21 $(C D K N 2 A / B), 1 \mathrm{p}$ and 19q. Mutations are indicated in different colours. TERT = telomerase reverse transcriptase; IDH1 = isocitrate dehydrogenase $1 ; I D H 2=$ isocitrate dehydrogenase $2 ; C D K N 2 A=$ cyclin-dependent kinase inhibitor $2 \mathrm{~A} ; C D K N 2 B=$ cyclindependent kinase inhibitor 2B; CDKN2C = cyclin-dependent kinase inhibitor $2 \mathrm{C}$; chromosome arm 1p; chromosome arm 19q; wildtype = no mutation found within the investigated loci.

\section{TERT mRNA expression levels}

RNA was available from 111 gliomas, of which 88 carried TERT promoter mutations $(-124 \mathrm{C}>\mathrm{T} n=67$; $-146 \mathrm{C}>\mathrm{T} n=21)$ and 23 were without the mutations. Analysis of quantitative real-time PCR data showed statistically significant higher levels of mRNA in gliomas with TERT promoter mutations than in wildtype tumors $(P$ $<0.0001, t$-test; Figure 2). Tumors harboring the $-124 \mathrm{C}>$ $\mathrm{T}$ mutation had a 14-fold increase in mRNA expression compared to wildtype lesions, whereas $-146 \mathrm{C}>\mathrm{T}$ tumors displayed a 7-fold increase. The difference in expression between tumors with $-124 \mathrm{C}>\mathrm{T}$ and $-146 \mathrm{C}>\mathrm{T}$ mutation was statistically significant $(P<0.0001, t$-test; Figure 2$)$.

\section{Relative telomere length and correlation with TERT promoter mutations}

Results from measurement of relative telomere length were available for 285 gliomas of which 190 were with and 95 were without TERT promoter mutations. Relative telomere length ranged between 0.01 and 4.24 with a 


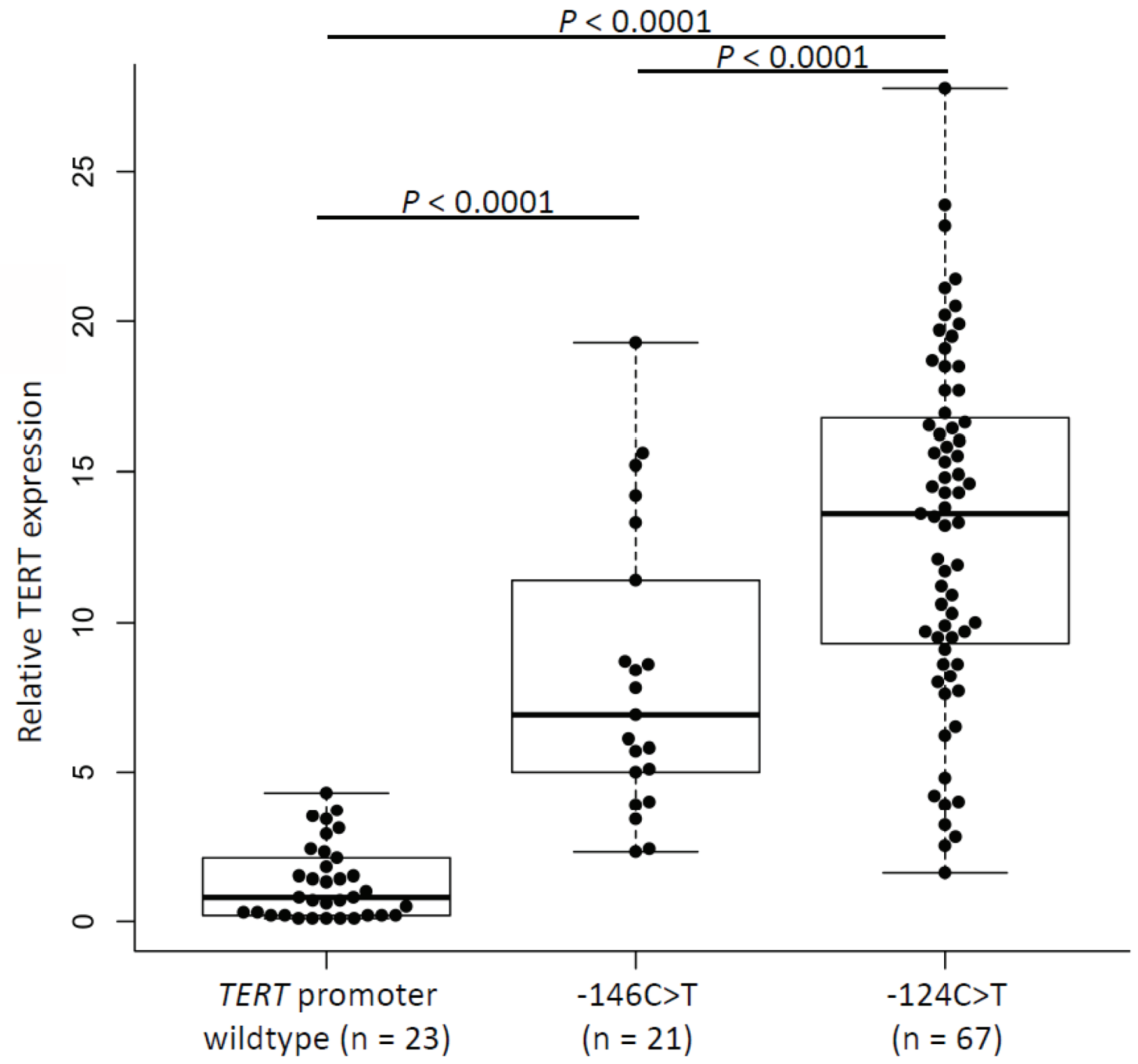

Figure 2: Relative TERT expression in glioma samples according to mutation status of the TERT promoter. Comparison of TERT mRNA expression in gliomas without and with TERT promoter mutations $-124 \mathrm{C}>\mathrm{T}$ or $-146 \mathrm{C}>\mathrm{T}$. Expression of TERT gene was normalized to GUSB expression, used as an internal standard, and quantification was performed by $\Delta \Delta \mathrm{C}_{\mathrm{T}}$ method with $\log 2$ transformation. Experiments were carried out in triplicates and box plots represent mean \pm standard error of means; $P$ (wildtype/ $-146 \mathrm{C}>\mathrm{T})<0.0001 ; P$ (Wildtype/-124C $>$ T $)<0.0001 ; P(-146 \mathrm{C}>\mathrm{T} /-124 \mathrm{C}>\mathrm{T})<0.0001 . P$-values were determined by $t$-test.

median value of 0.53 . Tumors carrying TERT promoter mutations had shorter telomeres (median 0.44) compared to tumors without mutations (median $0.94, P<0.0001$, $t$-test; Figure 3). Stratification of the data according to age showed that the differences in relative telomere lengths in tumors with TERT promoter mutations was statistically significant in patients with age $\leq 52$ years at diagnosis $(P<0.0001, t$-test; Supplementary Figure 1) but not in patients with age $>52$ $(P=0.3)$. Stratification of the data according to the combined $I D H$ and TERT promoter status revealed that only in the two groups that carry TERT promoter mutations (TERT promoter mutated and either $I D H$ mutated or wildtype) telomere lengths is statistically significant shorter than in tumors that carry neither of the mutations (Supplementary Figure 2).

\section{Correlation between relative telomere length and TERT mRNA expression}

We measured correlation between relative telomere length and TERT mRNA levels in 88 tumors for which both data were available. Data analysis showed a statistically significant inverse correlation between relative telomere length and TERT expression at mRNA level $(\mathrm{R}=$ $-0.24 ; P=0.02$; Supplementary Figure 3). 


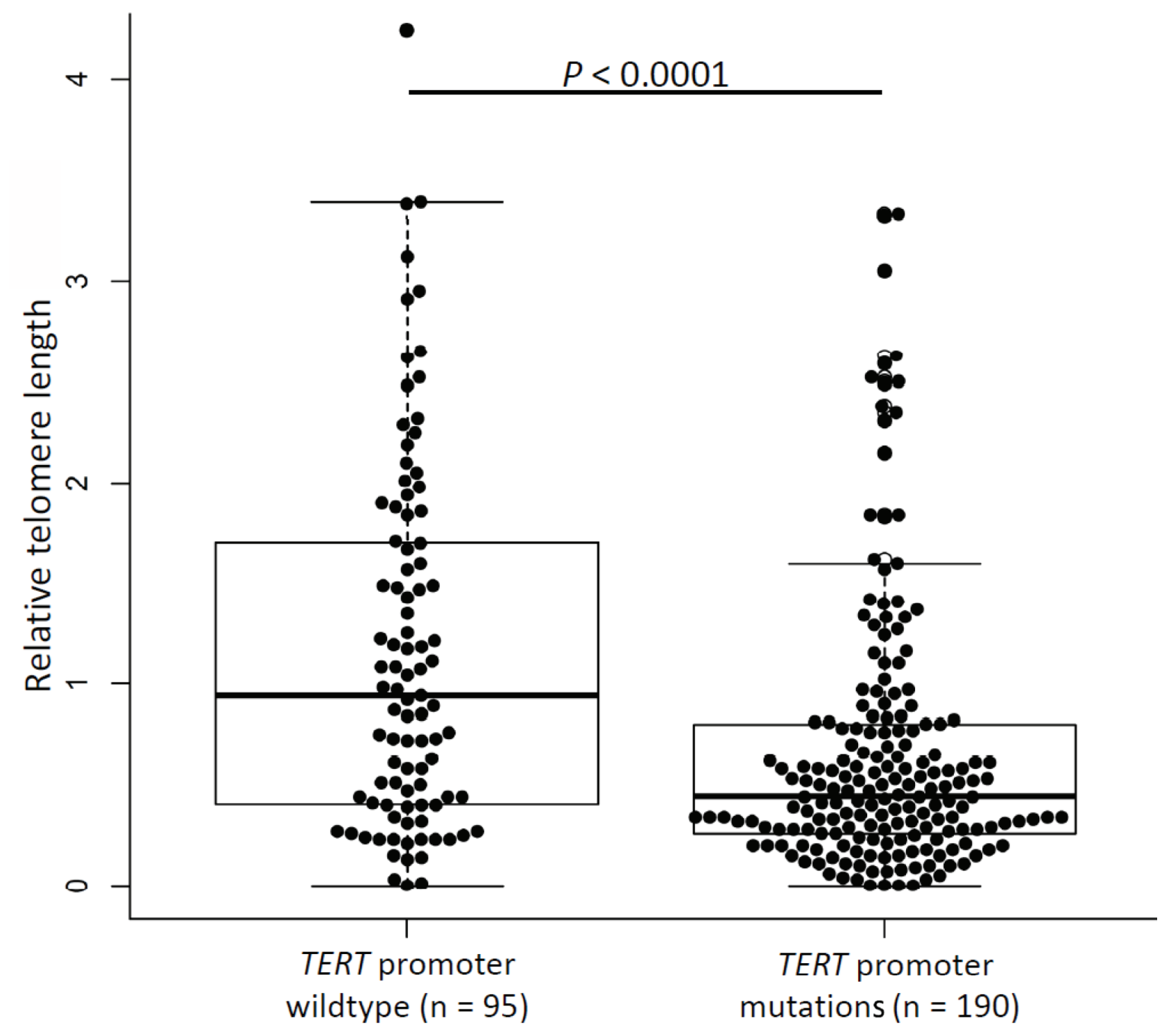

Figure 3: Telomere lengths in glioma tumors. Relative telomere length in gliomas without and with TERT promoter mutations. Experiments were carried out in triplicate and box plots represent mean \pm s.e.m. $P$-values were determined by $t$-test.

\section{Effect of TERT promoter mutations and alterations in other genes on survival}

To assess the effect of the investigated alterations, we conducted a survival analysis excluding those patients with incomplete mutation data $(n=46)$; further, patients aged younger than 20 years at diagnosis $(n=7)$ were excluded from the analysis.

Survival analysis of the different histological subgroups of glioma showed that patients suffering from primary glioblastomas had worst overall survival (median survival 14.0 months), followed by secondary glioblastomas (median survival 69.1 months); diagnoses of oligoastrocytomas, oligodendrogliomas and astrocytomas were associated with better survival than primary and secondary glioblastomas $(P<0.0001$; Figure 4$)$.
Stratification of patients based on the mutational status of the TERT promoter and IDH resulted in four groups with differing overall survival $(P<0.0001$; Figure 5). The group with TERT promoter mutations and without $I D H$ mutations showed worst overall survival (median survival 14.6 months), followed by the two groups without TERT promoter mutations that were either wildtype for $I D H$ (median survival 28.5 months) or carried IDH mutations (median survival 110.6 months). Best overall survival was associated with the presence of both TERT promoter and IDH mutations (median survival 246.5 months), which resembles oligodendroglial progression. A multivariate model that included age, grade, treatment and loss of $C D K N 2 A / B$ showed that the combined presence of TERT promoter and IDH mutations was the only independent factor $(\mathrm{HR}=0.22 ; 95 \%$ HR CI $0.082-0.59$; 

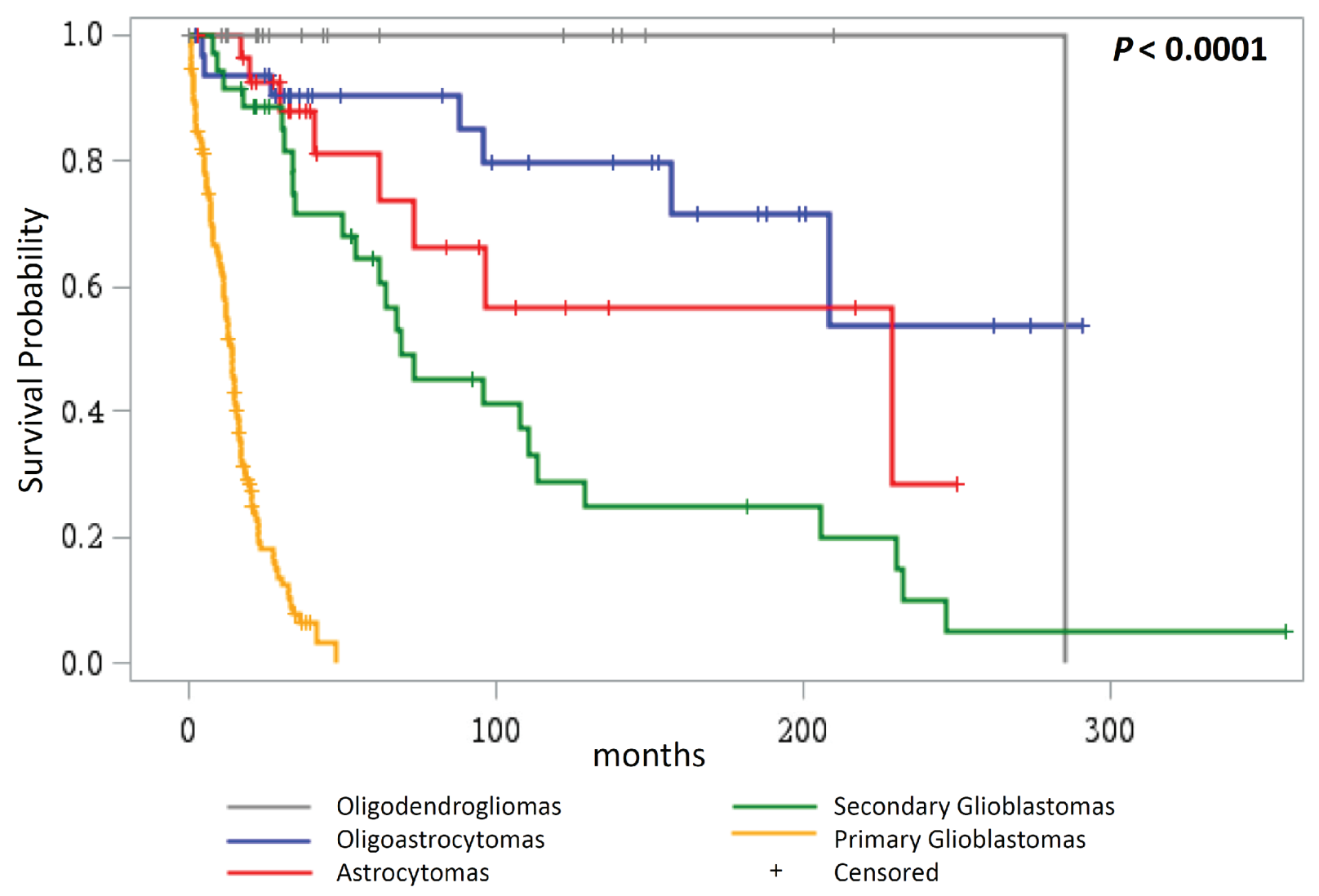

\begin{tabular}{|c|c|c|c|}
\hline & Total & Failed & censored \\
\hline Oligodendrogliomas & 19 & 1 & 18 \\
\hline Oligoastrocytomas & 33 & 7 & 26 \\
\hline Secondary Glioblastomas & 35 & 25 & 10 \\
\hline Primary Glioblastomas & 134 & 110 & 24 \\
\hline
\end{tabular}

Figure 4: Overall survival according to glioma histology. Kaplan Meier analysis of differences in overall survival in glioma patients according to their histology.

$P=0.03)$ (Supplementary Table 3 ). The adverse effect of only TERT promoter mutations was statistically significant in a model that did not include tumor grade and age $(\mathrm{HR}=$ 2.18 ; $95 \%$ HR CI $1.31-3.63 ; P=0.003$ ).

In survival analysis in patients with primary glioblastomas we did not observe any effect of the TERT promoter mutations. Both, patients with and without TERT promoter mutations, had a median survival of 14.0 months (Supplementary Figure 4). The multivariate model that included age, treatment, $I D H$ mutations, $1 \mathrm{p} / 19 \mathrm{q}$ codeletions and $C D K N 2 A$ deletions also did not show an effect of the TERT promoter mutations on patient survival (Table 3).

Patients with astrocytomas were also grouped according to their TERT promoter and IDH status as described before. We observed that the presence of only TERT promoter mutations was associated with worst survival (median survival 29.7 months), followed by the group with neither TERT promoter nor IDH mutations (median survival 96.2 months) and patients carrying only $I D H$ mutations (median survival 107.9 months). TERT promoter mutations in combination with $I D H$ mutations associated with best survival (median survival 229.3 months) (Supplementary Figure 5). A multivariate model that incorporated age, grade, treatment and loss of $C D K N 2 A / B$ showed that in the group of astrocytomas, concomitant TERT promoter and IDH mutations indicate good survival $(\mathrm{HR}=0.02 ; 95 \% \mathrm{HR}$ CI $0.001-0.542 ; P=$ 0.02 ) whereas $T E R T$ promoter mutations alone associated with poor survival $(\mathrm{HR}=37.7 ; 95 \%$ HR CI $1.63-870.8$; $P=0.02$ ) (Supplementary Table 4).

Further, we also investigated the independent effect of $1 \mathrm{p} / 19 \mathrm{q}$ codeletions, IDH mutations and TERT promoter mutations in astrocytomas. Patients with $1 \mathrm{p} / 19 \mathrm{q}$ codeletions were associated with better survival than patients without codeletions (96.2 months vs. 229.3 month, $P=0.0004$, Supplementary Figure 6A). Similarly, 


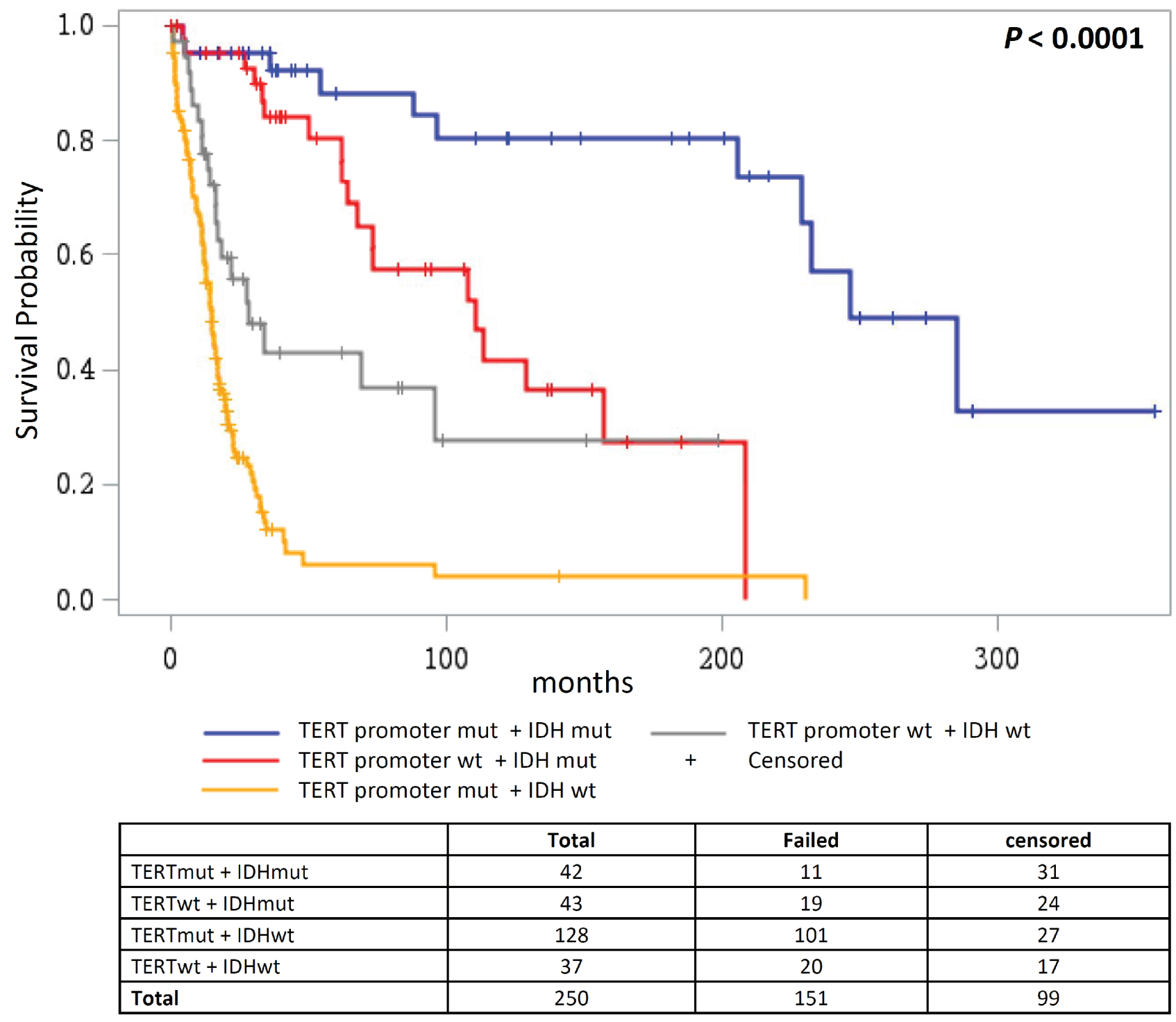

Figure 5: Overall survival according to combined status of TERT promoter and IDH mutations. Overall survival in glioma patients where patient groups are defined by the mutational status of the TERT promoter and IDH1/IDH2.

Table 3: Multivariate Model in primary Glioblastomas

\begin{tabular}{|c|c|c|c|c|c|}
\hline \multicolumn{2}{|l|}{ Parameter } & \multirow{2}{*}{$\frac{\boldsymbol{P}}{0.33}$} & \multirow{2}{*}{$\frac{\text { HR }}{0.77}$} & \multicolumn{2}{|c|}{$95 \%$ CI } \\
\hline TERT promoter & Mutation & & & 0.45 & 1.31 \\
\hline$I D H$ & Mutation & 0.16 & 0.43 & 0.13 & 1.41 \\
\hline $1 \mathrm{p} / 19 \mathrm{q}$ co-deletion & Deletion & 0.61 & 1.15 & 0.66 & 2.00 \\
\hline$C D K N 2 A / B$ & Deletion & 0.77 & 0.94 & 0.62 & 1.43 \\
\hline Treatment - Group & RT & 0.03 & 2.09 & 1.07 & 4.08 \\
\hline Treatment - Group & $\mathrm{TMZ}+\mathrm{ot}$ & 0.40 & 0.80 & 0.48 & 1.35 \\
\hline Treatment - Group & none & $<0.0001$ & 15.21 & 7.20 & 32.13 \\
\hline Age & & 0.01 & 1.03 & 1.01 & 1.05 \\
\hline
\end{tabular}


patients with $I D H$ mutations also showed better survival than without mutations (34.0 months vs. 205.8 months, $P<0.0001$, Supplementary Figure 6B). Overall, the presence of TERT promoter mutations was not associated with an effect on survival (Supplementary Figure 6C); however, when patients with only TERT promoter mutations were considered the effect on poor survival was statistically significant $(P<0.0001$; Supplementary Figure 6D). Here, patients with astrocytomas harboring TERT promoter mutations showed a median survival of 29.7 months compared to 107.9 months when mutations were not present.

A multivariate model that included TERT promoter mutations, $I D H$ mutations, deletions at $1 \mathrm{p} / 19 \mathrm{q}$ and $C D K N 2 A / B$, age, grade and treatment showed a protective effect for $1 \mathrm{p} / 19 \mathrm{q}$ codeletions on patients' survival $(\mathrm{HR}=$ $0.002 ; 95 \%$ HR CI $0.0001-0.09 ; P=0.002$ ) as well as poor survival for patients with TERT promoter mutations $(\mathrm{HR}=37.6 ; 95 \%$ HR CI $1.63-869.9 ; P=0.02)$ and patients with $C D K N 2 A$ deletions $(\mathrm{HR}=6.1 ; 95 \% \mathrm{HR} \mathrm{CI}$ $1.5-25.4 ; P=0.01$ ) (Supplementary Table 5).

In the group of oligoastrocytomas we observed that the effect of the mutations followed a pattern similar to that observed in astrocytomas. $1 \mathrm{p} / 19 \mathrm{q}$ codeletions were associated with better survival $(P=0.03$, Supplementary Figure 7A). Patients with $I D H$ mutations showed a median survival of 245.5 months compared to 230.3 months in patients wildtype for $I D H$; however, this difference was not statistically significant (Supplementary Figure 7B). TERT promoter mutations showed a statistically significant effect on poor survival only in patients without $1 \mathrm{p} / 19 \mathrm{q}$ co-deletions $(P=0.005$; Supplementary Figure $7 \mathrm{C}$ and 7D). The effect of the mutations or deletions in a multivariate model was not statistically significant (Supplementary Table 6 and 7).

We further stratified gliomas according to the disease grades, which resulted in one group with low grade gliomas that included 64 tumors with grade 2 astrocytomas, oligoastrocytomas and oligodendrogliomas. The second group comprised 185 high grade gliomas including primary glioblastomas and grade III/IV astrocytomas, oligoastrocytomas and oligodendrogliomas. Patients with low grade gliomas that showed $1 \mathrm{p} / 19 \mathrm{q}$ codeletions had a median survival of 285.7 months compared to 209.1 months for patients wildtype for $1 \mathrm{p} / 19 \mathrm{q}$ $(P=0.01$; Supplementary Figure 8A). IDH mutations did not have a statistically significant effect on survival (Supplementary Figure 8B; Supplementary Table 8). The independent effect of TERT promoter mutations without the concurrent $1 \mathrm{p} / 19 \mathrm{q}$ deletions could not be assessed (Supplementary Figure 8C; Supplementary Table 8).

A multivariate model on progression-free survival in low grade gliomas showed that TERT promoter mutations are associated with poor survival $(\mathrm{HR}=10.2 ; 95 \% \mathrm{HR}$ CI $1.9-55.9 ; P=0.007)$ and $1 \mathrm{p} / 19 \mathrm{q}$ codeletions have a protective effect $(\mathrm{HR}=0.03 ; 95 \%$ HR CI $0.004-0.173$; $P=0.0001)$ (Table 4).

In high grade gliomas $I D H$ mutations were associated with better survival (median survival wt: 15.0 vs. median survival mut: 64.5 months, $P<0.0001$; Supplementary Figure 9A); also 1p/19q co-deletions associated with better survival $(P<0.0001$; Supplementary Figure 9B). TERT promoter mutations entailed poorer survival (median survival of 15.2 months) compared to patients without mutations (30.5 months, $P=0.001$; Supplementary Figure 9C). A multivariate model that included TERT promoter and $I D H$ mutations, deletions at $1 \mathrm{p} / 19 \mathrm{q}$ and $C D K N 2 A / B$, treatment and age did not show statistically significant association of survival with any of the genetic alterations (Supplementary Table 9). However, exclusion of age from the model revealed association with TERT promoter mutations $(\mathrm{HR}=2.25 ; 95 \%$ HR CI 1.29-3.94; $P=0.005), I D H$ mutations ( $\mathrm{HR}=0.42$; $95 \%$ HR CI $0.19-0.91 ; P=0.03)$ and $1 \mathrm{p} / 19 \mathrm{q}$ codeletions $(\mathrm{HR}=0.12 ; 95 \%$ HR CI $0.023-0.59 ; P=0.01)$.

A multivariate model on progression-free survival in high grade gliomas showed no statistically significant effect of TERT promoter mutations but revealed a protective effect for $I D H$ mutations as well as for $1 p / 19 q$ deletions (Table 5).

Table 4: Multivariate Model for progression-free survival in Low Grade Gliomas

\begin{tabular}{|c|c|c|c|c|c|}
\hline \multicolumn{2}{|l|}{ Parameter } & \multirow{2}{*}{$\frac{P}{0.01}$} & \multirow{2}{*}{$\begin{array}{c}\text { HR } \\
10.21\end{array}$} & \multicolumn{2}{|c|}{$95 \% \mathrm{CI}$} \\
\hline TERT promoter & Mutation & & & 1.87 & $\mathbf{5 5 . 8 7}$ \\
\hline$I D H$ & Mutation & 0.10 & 2.03 & 0.87 & 4.73 \\
\hline $1 p / 19 q$ co-deletion & Deletion & 0.0001 & 0.03 & 0.004 & 0.17 \\
\hline$C D K N 2 A / B$ & Deletion & 0.43 & 1.35 & 0.64 & 2.85 \\
\hline Treatment - Group & $\mathrm{CCNU}$ & 0.43 & 0.60 & 0.17 & 2.14 \\
\hline Treatment - Group & Carmustin & 0.23 & 3.89 & 0.42 & 36.28 \\
\hline Treatment - Group & $\mathrm{PC}$ & 0.16 & 1.70 & 0.81 & 3.56 \\
\hline Treatment - Group & none & 0.005 & 0.22 & 0.08 & 0.63 \\
\hline Age & & 0.81 & 1.00 & 0.97 & 1.04 \\
\hline
\end{tabular}


Table 5: Multivariate Model on progression-free survival in High Grade Gliomas

\begin{tabular}{l|l|c|c|c|c|}
\hline Parameter & \multicolumn{2}{c}{$\boldsymbol{P}$} & HR & \multicolumn{2}{c}{$\mathbf{9 5 \%}$ CI } \\
\hline TERT promoter & Mutation & 0.39 & 1.27 & 0.73 & 2.21 \\
\hline$I D H$ & Mutation & $\mathbf{0 . 0 1}$ & $\mathbf{0 . 3 6}$ & $\mathbf{0 . 1 6}$ & $\mathbf{0 . 8 2}$ \\
\hline $1 \mathrm{p} / 19 \mathrm{q}$ co-deletion & Deletion & $\mathbf{0 . 0 2}$ & $\mathbf{0 . 0 9}$ & $\mathbf{0 . 0 1}$ & $\mathbf{0 . 7 1}$ \\
\hline CDKN2A/B & Deletion & 0.65 & 1.10 & 0.74 & 1.64 \\
\hline Treatment & BEV & 0.55 & 1.33 & 0.53 & 3.33 \\
\hline Treatment & CCNU & 0.15 & 2.47 & 0.71 & 8.54 \\
\hline Treatment & Carmustin & 0.08 & 0.55 & 0.28 & 1.09 \\
\hline Treatment & PC & 0.76 & 1.37 & 0.19 & 10.00 \\
\hline Treatment & none & 0.13 & 0.57 & 0.27 & 1.18 \\
\hline
\end{tabular}

We further investigated the effect of TERT promoter mutations on overall survival according to different treatment regimens in patients with high grade gliomas. Therefore, patients were stratified into three groups, where group 1) did not receive any treatment, group 2) received radiotherapy alone or in combination with procarbazine or temozolomide and group 3) received temozolomide and radiotherapy combined with a third adjuvant. Patients who did not receive any treatment showed poor overall survival, followed by patients in group 2). In both groups the presence of TERT promoter mutations showed no effect. However, for patients in group 3) we observed that those without TERT promoter mutations (median survival 64.5 months) showed better overall survival than patients with the mutations (median survival 22.2 months; $P=0.0001$; Figure 6; Supplementary Figure 10A). The same trend was also observed when patients with only primary glioblastomas were analyzed $(P=0.0001$; Supplementary Figure 10B). Here, patients in group 3) showed better survival than patients in group 1) or 2) and again, especially patients with TERT promoter wildtype tumors (median survival 28.0 months) benefitted from the combination therapy (temozolomide + radiotherapy + adjuvant) in comparison to patients wildtype for the TERT promoter (median survival 20.1 months).

\section{Comparison between alterations in glioma tumors and matched recurrences}

In total, 22 recurrences matched to 20 glioma tumors were available. In 18 cases, material from the patients' initial tumor and one recurrence was accessible and in another two cases tumor material from the initial lesion and two recurrences each was available (Supplementary Table 10). In addition to the described genetic alterations (TERT promoter, IDH1/2, CDKN2A/B deletions, 1p/19q codeletions) we included data on rs 2853669 , a common SNP within the investigated fragment of the TERT promoter, in order to serve as an internal control that tissues were acquired from the same patients. In 15 cases, glioma tumors and their matched recurrences were consistent in all of the investigated alterations. In contrast, in another 5 pairs, tumors varied in one or more alterations, when compared to their recurrences. In four pairs, an initial $C D K N 2 A / B$ deletion could not be detected in the recurrences. For two pairs the initial TERT promoter mutations and one $I D H 1$ mutation were not found in the recurrences and those also showed differences in their histology (Supplementary Table 10).

We also assessed survival in patients with initial tumors and recurrences based on TERT promoter mutation status. Two patients (BT-163 and BT-171) that had TERT promoter mutations in the initial tumors but not in the recurrence had median progression free survival of 65.3 months compared to 12.3 months for those patients $(n=3)$ that did not have the mutations in both initial tumors and recurrences. The median progression free survival for patients $(n=15)$ that had TERT promoter mutations in both initial tumors and recurrences was 8.5 months. The difference in progression free survival in three categories was, however, not statistically significant $(P=0.29$; Supplementary Figure 11A). We also found a similar difference in overall survival in patients with recuurences based on mutational status of the TERT promoter. While the patients without mutations in initial tumors and recurrences showed overall median survival of 30.5 months compared to 16.2 months in patients with TERT promoter mutations in both. The patients with mutations in initial tumors and no mutations in the recurrence had better survival than the other two categories; however, overall difference was not statistically significant (Supplementary Figure 11B).

\section{DISCUSSION}

Over the years different studies have demonstrated that the classification of gliomas based on their molecular profiles, in particular with inclusion of IDH mutations, results in subgroups with prognostic significance $[13,14$, 


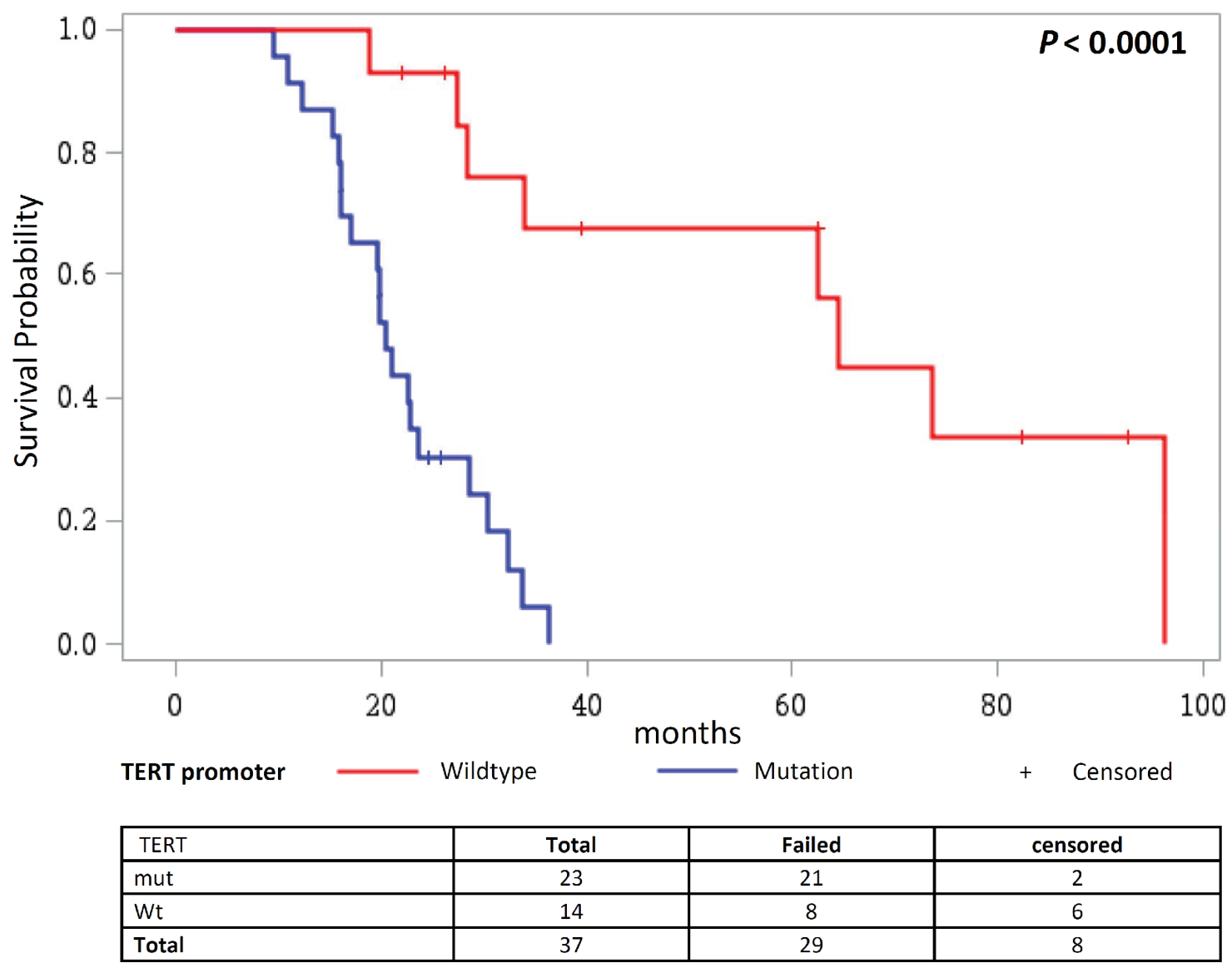

Figure 6: Overall survival in patients receiving TMZ and radiotherapy combined with a third adjuvant stratified according to the $\boldsymbol{T E R T}$ promoter status. Kaplan Meier analysis on overall survival in glioma patients receiving TMZ and radiotherapy combined with a third adjuvant, where patients are stratified according to their mutational status of the TERT promoter.

26]. The discovery of mutations in the TERT promoter and subsequent reports of their occurrence at a high frequency in gliomas has resulted in further refinement of glioma classification [23, 24]. In this study, carried out on different sub-types of gliomas, we corroborated that the distribution of the TERT promoter and IDH mutations follow histological classification and predict the prognostic outcome of the disease, which, depending on the histological sub-type, is further influenced by deletions at 1p/19q loci [27]. Besides reporting a high frequency of TERT promoter mutations in different glioma types, we describe the correlations with $I D H$ mutations and deletions at $1 \mathrm{p}, 19 \mathrm{q}$ and $C D K N 2 A / B$ loci that have prognostic implications. Although the two main TERT promoter mutations create the exact same consensus sites for Ets/TCF transcription factors, our data suggest differences in the levels of increased TERT expression based on the mutational position [28]. Moreover, the presence of TERT promoter mutations strongly demonstrates the mechanistic relevance of telomere biology in cancer progression, which is predicated on the finding of shorter telomeres in tumors with mutations than without mutations.

The distribution of TERT promoter mutations in different glial tumors followed the reported pattern with highest frequencies being present in primary glioblastomas, followed by oligodendrogliomas, oligoastrocytomas and astrocytomas [17, 24, 25, 29-35]. The divergence between primary and secondary glioblastomas, considered as two distinct entities, was supported strongest by the incidence of IDH mutations, which are presumed as early initiating events in the development of secondary glioblastomas either via astrocytic or oligoastrocytic progression. The $I D H$ mutations are conspicuously rare in primary glioblastomas $[13,14]$. The high frequency of TERT promoter mutations in primary glioblastomas and an inverse association between $I D H$ and $T E R T$ promoter mutations in astrocytomas and secondary glioblastomas suggests that those patterns of mutations represent astrocytic progression. The distinctive alteration in oligodendrogliomas is the combined loss of $1 p$ and $19 q[6,15$, 36]. Within this group, as reported earlier, we found that the TERT promoter mutations correlated with $1 \mathrm{p} / 19 \mathrm{q}$ codeletions and $I D H$ mutations $[24,25]$. Those observations, in combination with previous reports, lead to the conclusion that co-occurrence of mutations in IDH and the TERT promoter reflect a mutational signature of oligodendrogliomas, whereas the presence of either TERT promoter or $I D H$ mutations is a feature of astrocytic progression $[25,37]$. 
In a set of available recurrences we found that in majority genotypes corresponded with the matched primary tumors. However, the two pairs with divergent status of TERT promoter showed mutations in the primary lesion but not in the recurrences. Generally, variations in genotypes can be ascribed either to detection limits of applied methods influenced by tumor heterogeneity, or varying genotypes in primary and recurrent tumor. An earlier report in primary glioma tumors and recurrences showed that recurrent tumors are often seeded by cells derived from the initial tumor at a very early stage of their evolution, which ultimately leads to deviating genotypes in primary tumors and recurrences [38].

The distribution of genetic alterations in primary tumors according to the course of glial progression was also evident in data from survival analysis. The combined mutational status profile of the TERT promoter and IDH reflected the survival in different histological sub-types of gliomas. Lowest survival in patients with only TERT promoter mutations and longest survival for patients with both TERT promoter and IDH mutations are most likely indicative of primary glioblastoma and oligodendroglial histologies, respectively, rather than any direct biological effect of the altered genes. Those observations were in accordance with earlier reports [24, 25, 27]. Accordingly, TERT promoter mutations did associate strongly with poor survival in the overall analysis of high grade tumors that included primary glioblastomas, high grade astrocytoma and oligodendrogliomas $[27,33]$. As shown earlier we observed poor survival in patients with high grade gliomas that had only TERT promoter mutations [24, 39]. However, in contrast to earlier reports in this study we did not observe any association between TERT promoter mutations and overall survival in patients with primary gliobastoms [40, 41]. The overwhelming occurrence of the TERT promoter mutations and in general poor survival associated with primary glioblastoma probably precludes such an association $[1,5]$.

An earlier study showed the effect of TERT promoter mutations on poor survival in primary gliobastoma patients that did not receive chemotherapy [40]. In this study we observed that patients with high grade tumors that did not receive treatment survived least. However, the differences in survival with and without TERT promoter mutations was significant only in those patients that were treated with adjuvant therapy together with alkylating agents either temozolomide or dacarbazine.

In astrocytomas, survival was primarily defined by $I D H$ mutations and $1 \mathrm{p} / 19 \mathrm{q}$ deletions. Patients with these alterations associated with significantly beneficial prognosis; however, TERT promoter mutations in the absence of the $1 \mathrm{p} / 19$ deletions, though rare, showed debilitating effect on patient survival. In general patients with oligoastrocytomas and oligodendrogliomas followed a similar pattern of survival as astrocytic patients; however, a near absence of TERT promoter mutations without $I D H$ mutations precluded an independent assessment of the effect of the former alterations as has been the case in earlier studies [24]. The same trend was also discernible for all low grades tumors put together; nevertheless a multivariate model for progression free survival did show association of worst prognosis with TERT promoter mutations and best prognosis for patients with $1 \mathrm{p} / 19 \mathrm{q}$ deletions.

The TERT promoter mutations occur mainly at -124 bp and -146 bp positions from ATG start site of TERT promoter. Those positions correspond to the genomic coordinates of Chr5:1, 295, 228 (hg19 co-ordinate) and Chr5:1, 295, 250 (hg19 co-ordinate), which led to the erroneous labeling of the alterations as C228T and C250T $[42,43]$. Although all reported mutations in the TERT promoter including the causal $-57 \mathrm{C}>$ A germline single nucleotide change reported in a melanoma family are joined by a common feature of de novo creation of CCGGAA/T sequence, which, besides being a recognition motif for Ets transcription factors, is a specific binding motif for ternary complex factors like Elk1 and Elk4 [23]. The mutations as presumed resulted in increased promoter activity and have been shown as the main mechanism for $T E R T$ up-regulation, which conceivably would lead to increased telomerase levels $[32,44,45]$. With the exception of melanoma where the $-146 \mathrm{C}>\mathrm{T}$ mutation is more frequent than any other base change in the TERT promoter, in most other malignancies $-124 \mathrm{C}>\mathrm{T}$ has been reported to be the most common alteration [28]. In this study we observed that while tumors with any of the two mutations showed significantly increased TERT transcription, the increase in the expression in tumors with the $-124 \mathrm{C}>\mathrm{T}$ mutation was significantly higher than in tumors with the $-146 \mathrm{C}>\mathrm{T}$ mutations. One of the plausible reasons for the novel observation of differences in TERT transcription due to two mutations with apparently same phenotype could be context specific variations in accessibility to transcription factors through chromatin remodeling.

The promoter mutations not only affected TERT transcription, we also for the first time in glioma observed influence on relative telomere lengths. The tumors with TERT promoter mutations in accordance with earlier observations in thyroid cancer had shorter telomeres than tumors without the mutations [44]. Presumed acquisition of the somatic TERT promoter mutations at the point of telomere crisis in the course of cellular transformation has been cited as a reason for an association with telomere length. The critically shortened telomeres in oncogenedriven proliferating tumor cells, in the absence of active telomerase, are thought to be causal in cell cycle arrest through activation of signaling cascade involving check point inhibitors [46, 47]. Bypass of replicative senescence and continued telomere attrition in affected cells are postulated to be causal for unstable genomes through cycles of end-fusions and breakages [48]. Selection pressure, leading to acquisition of TERT promoter mutations and regeneration of telomerase to overcome telomeric crisis, probably provides the context for shorter telomeres in tumors with mutations [46]. 
Tumors with IDH mutations in the absence of TERT promoter mutations had telomere lengths similar to those without mutations. Biologically $I D H$ mutations are known to deregulate metabolic process. Mutant $I D H$ proteins prevent normal conversion of isocitrate and lead to formation of the R-enantiomer of 2-hydroxylglutarate (R-2-HG) instead of a-ketoglutarate (a-KG) [49]. Increased levels of R-2-HG, besides effecting accumulation of hypoxia-inducible factor 1a, also alters epigenetic modification of histone and DNA methylation through inhibition of a-KG dependent dioxygenases [50]. While TERT promoter mutations independently associate with poor in survival in many cancers, the mutations also associate with reduced telomere length. Here we show that $I D H$ mutations that are in general markers of better prognosis in glioma do not associate with changed telomere length in tumors.

An inverse correlation between relative telomere length and TERT expression in this study was in accorandance with an earlier report that showed shorter telomere length in gliobastoma that were positive for TERT expression and telomerase activity than those glioblastoma that were negative for both [51]. Conversely, the inverse correlation between the two also supported the observation of shorter telomeres in tumors with TERT promoter mutations than without mutations as an increased TERT expression is associated with the presence of mutations.

Development of glioma subtypes along discrete pathways is characterized by the different genetic alterations that emerge along the way [3, 5, 13, 24, 52]. TERT promoter mutations add further complexity to the scenario but at the same time hold clear potential as prognostic markers. A combination of TERT promoter and $I D H$ mutations support placement of gliomas into the subgroups, which is also reflected in survival and can be of considerable use in making appropriate treatment decisions. Data suggest that patients with TERT promoter mutations in tumors probably require more aggressive treatment than their wildtype counterparts. Further studies will help in elucidating the value of TERT promoter mutations as biomarkers in clinical practice and eventual therapeutic targets. Expression data and an association with shorter telomeres already strongly indicate the role of the TERT promoter mutations not only in glioma, but many other cancer types, and future functional studies will aid placing the TERT promoter mutations into the right context.

\section{METHODS}

\section{Patients and tumor samples}

Informed consent was obtained from all patients included in the study. The study was approved by the appropriate ethical committee. 303 primary tumors and additional 22 recurrences were collected between March
2010 and August 2013. Fresh tumor tissue was obtained directly from the operating theatre, snap-frozen and processed for further analysis as described below. In the majority of cases tumor samples were taken based on the MRI image using neuronavigation. Neuropathological diagnosis was made from paraffin-embedded tissue by a board-certified neuropathologist. Clinical data was collected in a database which included parameters such as patient age at first diagnosis, sex, histology at primary diagnosis and at recurrence, progression-free survival and overall survival or date of last patient contact. Progressionfree survival was assessed on MRI imaging according to Macdonald criteria. Follow-up data was obtained from the family physicians and from the German Cancer Registry. The patients were treated according to the appropriate guidelines or in clinical trials. The date and number of surgeries, type and number of radiation and chemotherapy were documented.

\section{DNA and RNA extraction}

From fresh frozen glioma samples, DNA and RNA were extracted using the QIAGEN AllPrep DNA/RNA MiniKit. Tissues were homogenized in a Tissuelyser LT (Qiagen, Hilden, Germany) with $5 \mathrm{~mm}$ stainless steel beads in $600 \mathrm{ml}$ RLT buffer and were further processed. Concentrations of total DNA and RNA in all samples were measured using an ultraviolet-visible spectrophotometer (NanoDrop Technologies, Wilmington, USA) and absorption ratio at 260/280 $\mathrm{nm}$ was determined. RNA consistency was examined for a representative number of samples using the Bioanalyzer 2100 System (Agilent Technologies, Palo Alto, CA) with the corresponding RNA nanochips.

\section{Mutational analysis by sequencing}

Mutations in the TERT promoter region (from position -27 to -286 from ATG start site) were identified by PCR and Sanger sequencing. Mutational status of IDH1 was crossvalidated by sequencing for all available samples. Mutations in $\mathrm{IDH} 2$ were confirmed by sequencing if the respective probes indicated a signal in MLPA. PCR was carried out in a $10 \mu \mathrm{l}$ volume containing $10 \mathrm{ng} \mathrm{DNA}, 50 \mathrm{mM} \mathrm{KCl}, 0.11$ $\mathrm{mM}$ dNTP and $0.11 \mathrm{mM}$ of each primer. Concentrations of $\mathrm{MgCl}_{2}$ and other additives and temperature conditions were adjusted according to the primer sequences (Supplementary Table 11). Amplified products were purified with Exosap (GE Healthcare, Buckinghamshire, UK) to remove unused primer and were subjected to 35 cycles of sequencing reaction with a di-deoxy terminator kit and forward and reverse primers in separate reactions (BigDyeTerminator v3.1 Cycle Sequencing Kit, Applied Biosystems, Austin, TX, USA). Sequencing reaction products were precipitated with ethanol and analyzed on a capillary sequencer (AbiPrism 3130xl Genetic Analyzer). The sequencing data were 
analyzed using Geneious Pro 5.6.5 software with reference to the sequences from the NCBI gene database, TERT (chr5: 1, 295, 071-1, 295, 521), IDH1 (NC_000002.12) and IDH2 (NC_000015.).

\section{Multiplex ligation-dependent probe amplification (MLPA)}

To detect deletions at various relevant sites we used the P088-C1 probemix (SALSA MLPA P088 Oligodendroglioma probemix, MRC-Holland, The Netherlands). This probemix can be used to detect loss of chromosome arms $1 \mathrm{p}$ and $19 \mathrm{q}$, as well as copy number changes in $C D K N 2 A$ and $C D K N 2 B$ genes. Furthermore, it contains mutation-specific probes for IDH1 (R132H and R132C) and IDH2 (R172K and R172M). In addition, 14 reference probes are included, detecting different chromosomal locations known to be silent in glioma. Since probes for hot spot mutations in IDH1 (R132H and R132C) and IDH2 (R172K and R172M) were not established for the use in tumor tissue by the supplier, results were crossvalidated by Sanger sequencing and we can confirm consistent results for both methods. Fifteen glioma samples were analyzed with a second kit also covering the 9p21 locus to compare results (SALSA MLPA ME024 9p21 CDKN2A/2B; MRC Holland, The Netherlands). The method was performed following the suggested protocol. In short, $50 \mathrm{ng}$ of DNA per sample were subjected to $16 \mathrm{~h}$ of incubation with the probe mix and afterwards processed in a ligation reaction, followed by a multiplex PCR. Fragment analysis was performed on a capillary sequencer (AbiPrism 3130xl Genetic Analyzer). The results were evaluated using Coffalyser software (MRC-Holland); threshold to define deletions was set at the suggested delta value of 0.3 .

\section{Measurement of TERT mRNA expression}

For measurement of TERT expression, reverse transcription reaction was performed using between 0.75 and $1.0 \mathrm{mg}$ RNA and random hexamer primers using a cDNA synthesis kit (Thermo Scientific, Waltham, USA). TERT expression levels were then determined by quantitative real-time PCR using a Sybr Green kit (Qiagen). The real-time PCR was carried out in triplicates on a 384-well layout using primers specific for TERT (Supplementary Table 11) and primers for the GUSB gene (Qiagen), a housekeeping gene used as an internal standard. TERT expression levels were calculated using GUSB expression as a reference and relative quantification was performed using the $\Delta \Delta \mathrm{C}_{\mathrm{T}}$ method and $\log 2$ transformation.

\section{Measurement of telomere length}

Relative telomere length in tumor DNA was measured using the monochrome multiplex PCR assay as described previously including minor modifications
$[53,54]$. Described briefly, reactions were performed in triplicates in an optical 384-well reaction plate in a $10 \mu \mathrm{l}$ reaction volume using $2 \mu \mathrm{l}$ of $5 \mathrm{X}$ HOT FIREPol Probe qPCR Mix Plus with ROX (Solis BioDyne), $1.5 \mu \mathrm{M}$ of Syto 9 (Invitrogen) and 5-10 ng of genomic DNA. Four primers (Supplementary Table 11) were used in each reaction to amplify telomere DNA (telg at $200 \mathrm{nM}$ and telc at $400 \mathrm{nM}$ ) and the albumin gene (albugcr2 at $200 \mathrm{nM}$ and albdgcr2 at $400 \mathrm{nM}$ ). Real-time PCR experiments were performed on an Applied Biosystems Viia-7 instrument using two simultaneous programs to acquire the respective CT values for telomere sequences and the albumin gene. The conditions for telomere sequence amplification were $95^{\circ} \mathrm{C} / 15 \mathrm{~min}, 2$ cycles of $95^{\circ} \mathrm{C} / 20 \mathrm{sec}$ and $49^{\circ} \mathrm{C} / 1$ min, followed by 25 cycles of $85^{\circ} \mathrm{C} / 20 \mathrm{sec}$ with signal acquisition at $59^{\circ} \mathrm{C} / 30 \mathrm{sec}$. The conditions for albumin gene were 35 cycles of $95^{\circ} \mathrm{C} / 15 \mathrm{sec}, 85^{\circ} \mathrm{C} / 30 \mathrm{sec}$, with signal acquisition at $84^{\circ} \mathrm{C} / 30 \mathrm{sec}$. The specificity of all amplifications was determined by melting curve analysis done at default settings $\left(95^{\circ} \mathrm{C} / 15 \mathrm{sec}, 60^{\circ} \mathrm{C} / 1 \mathrm{~min}\right.$ with continuous signal acquisition at $0.05^{\circ} \mathrm{C} / \mathrm{sec}$ ramping, $\left.95^{\circ} \mathrm{C} / 15 \mathrm{sec}\right)$. Seven concentrations of a reference DNA sample (genomic DNA pooled from 10 healthy individuals) were included in triplicates in a 2-fold serial dilution (from $20 \mathrm{ng}$ to $0.3 \mathrm{ng}$ ) to generate standard curves for telomere (T) and albumin (S) PCR products, respectively. The quality control was performed using the Applied Biosystems Viia7 software. The standard curve was used to quantify the telomere and albumin genes based on the respective CT values and the obtained triplicate values were averaged. The relative telomere lengths was expressed as the ratio between $\mathrm{T} / \mathrm{S}$. Inter-assay variation and intra-assay variation was determined by duplicating the reference DNA for all the dilutions in all the assays performed.

\section{Statistical analysis}

Associations between the TERT promoter mutations and other parameters were determined by chi ${ }^{2}$-test. A difference was considered statistically significant if the $P$-value was 0.05 or smaller. Odds ratios were calculated to assess the effect size. Overall survival was studied using univariate and multivariate Cox proportional hazards modeling, where appropriate. Survival endpoints were analyzed by Kaplan-Meier estimates and differences between the curves were analyzed with log-rank test.

\section{REFERENCES}

1. Ostrom QT, Bauchet L, Davis FG, Deltour I, Fisher JL, Langer CE, Pekmezci M, Schwartzbaum JA, Turner MC, Walsh KM, Wrensch MR, Barnholtz-Sloan JS. The epidemiology of glioma in adults: a "state of the science" review. Neuro Oncol. 2014.

2. Louis DN, Ohgaki H, Wiestler OD, Cavenee WK, Burger PC, Jouvet A, Scheithauer BW, Kleihues P. The 
WHO classification of tumours of the central nervous system. Acta neuropathologica. 2007; 114:97-109.

3. Goodenberger ML, Jenkins RB. Genetics of adult glioma. Cancer genetics. 2012; 205:613-621.

4. Ostrom QT, Gittleman H, Farah P, Ondracek A, Chen Y, Wolinsky Y, Stroup NE, Kruchko C, Barnholtz-Sloan JS. CBTRUS statistical report: Primary brain and central nervous system tumors diagnosed in the United States in 2006 2010. Neuro Oncol. 2013; 15:ii1-56.

5. Ohgaki H, Kleihues P. Genetic pathways to primary and secondary glioblastoma. The American journal of pathology. 2007; 170:1445-1453.

6. Gupta M, Djalilvand A, Brat DJ. Clarifying the diffuse gliomas: an update on the morphologic features and markers that discriminate oligodendroglioma from astrocytoma. American journal of clinical pathology. 2005; 124:755-768.

7. Tilgner J, Herr M, Ostertag C, Volk B. Validation of intraoperative diagnoses using smear preparations from stereotactic brain biopsies: intraoperative versus final diagnosis - influence of clinical factors. Neurosurgery. 2005; 56:257-265; discussion 257-265.

8. Prabhu S, Harris F, Lea R, Snape TJ. Small-molecule clinical trial candidates for the treatment of glioma. Drug discovery today. 2014.

9. Krell D, Mulholland P, Frampton AE, Krell J, Stebbing J, Bardella C. IDH mutations in tumorigenesis and their potential role as novel therapeutic targets. Future oncology. 2013; 9:1923-1935.

10. van den Bent MJ. Interobserver variation of the histopathological diagnosis in clinical trials on glioma: a clinician's perspective. Acta neuropathologica. 2010; 120:297-304.

11. Weller M, Felsberg J, Hartmann C, Berger H, Steinbach JP, Schramm J, Westphal M, Schackert G, Simon M, Tonn JC, Heese O, Krex D, Nikkhah G, Pietsch T, Wiestler O, Reifenberger $\mathrm{G}$, et al. Molecular predictors of progression-free and overall survival in patients with newly diagnosed glioblastoma: a prospective translational study of the German Glioma Network. Journal of clinical oncology : official journal of the American Society of Clinical Oncology. 2009; 27:5743-5750.

12. Okita Y, Narita Y, Miyakita Y, Ohno M, Matsushita Y, Fukushima S, Sumi M, Ichimura K, Kayama T, Shibui S. IDH1/2 mutation is a prognostic marker for survival and predicts response to chemotherapy for grade II gliomas concomitantly treated with radiation therapy. International journal of oncology. 2012; 41:1325-1336.

13. Ichimura K, Pearson DM, Kocialkowski S, Backlund LM, Chan R, Jones DT, Collins VP. IDH1 mutations are present in the majority of common adult gliomas but rare in primary glioblastomas. Neuro Oncol. 2009; 11:341-347.

14. Appin CL, Brat DJ. Molecular genetics of gliomas. Cancer journal. 2014; 20:66-72.

15. Zhao J, Ma W, Zhao H. Loss of heterozygosity $1 \mathrm{p} / 19 \mathrm{q}$ and survival in glioma: a meta-analysis. Neuro Oncol. 2014; 16:103-112.
16. Remke M, Ramaswamy V, Peacock J, Shih DJ, Koelsche C, Northcott PA, Hill N, Cavalli FM, Kool M, Wang X, Mack SC, Barszczyk M, Morrissy AS, Wu X, Agnihotri S, Luu B, et al. TERT promoter mutations are highly recurrent in SHH subgroup medulloblastoma. Acta neuropathologica. 2013; 126:917-929.

17. Koelsche C, Sahm F, Capper D, Reuss D, Sturm D, Jones DTW, Kool M, Northcott PA, Wiestler B, Bohmer K, Meyer J, Mawrin C, Hartmann C, Mittelbronn M, Platten M, Brokinkel B, et al. Distribution of TERT promoter mutations in pediatric and adult tumors of the nervous system. Acta neuropathologica. 2013; 126:907-915.

18. Liu X, Wu G, Shan Y, Hartmann C, von Deimling A, Xing M. Highly prevalent TERT promoter mutations in bladder cancer and glioblastoma. Cell Cycle. 2013; 12:1637-1638.

19. Heidenreich B, Rachakonda PS, Hemminki K, Kumar R. TERT promoter mutations in cancer development. Curr Opin Genet Dev. 2014; 24:30-37.

20. Wang K, Liu T, Liu L, Liu J, Liu C, Wang C, Ge N, Ren H, Yan K, Hu S, Bjorkholm M, Fan Y, Xu D. TERT promoter mutations in renal cell carcinomas and upper tract urothelial carcinomas. Oncotarget. 2014; 5:1829-1836.

21. Wang K, Liu T, Ge N, Liu L, Yuan X, Liu J, Kong F, Wang C, Ren H, Yan K, Hu S, Xu Z, Bjorkholm M, Fan Y, Zhao S, Liu C, et al. TERT promoter mutations are associated with distant metastases in upper tract urothelial carcinomas and serve as urinary biomarkers detected by a sensitive castPCR. Oncotarget. 2014; 5:12428-12439.

22. Delude C. TERT Promoter Eyed With Suspicion and Hope. Journal of the National Cancer Institute. 2014; 106.

23. Horn S, Figl A, Rachakonda PS, Fischer C, Sucker A, Gast A, Kadel S, Moll I, Nagore E, Hemminki K, Schadendorf D, Kumar R. TERT promoter mutations in familial and sporadic melanoma. Science. 2013; 339:959-961.

24. Killela PJ, Pirozzi CJ, Healy P, Reitman ZJ, Lipp E, Rasheed BA, Yang R, Diplas BH, Wang Z, Greer PK, Zhu H, Wang CY, Carpenter AB, Friedman H, Friedman AH, Keir ST, et al. Mutations in IDH1, IDH2, and in the TERT promoter define clinically distinct subgroups of adult malignant gliomas. Oncotarget. 2014; 5:1515-1525.

25. Arita H, Narita Y, Fukushima S, Tateishi K, Matsushita Y, Yoshida A, Miyakita Y, Ohno M, Collins VP, Kawahara N, Shibui S, Ichimura K. Upregulating mutations in the TERT promoter commonly occur in adult malignant gliomas and are strongly associated with total $1 \mathrm{p} 19 \mathrm{q}$ loss. Acta Neuropathol. 2013; 126:267-276.

26. Olar A, Prabhu SS. Molecular classification of diffuse gliomas. Oncology. 2013; 27:514-518520.

27. Labussiere M, Di Stefano AL, Gleize V, Boisselier B, Giry M, Mangesius S, Bruno A, Paterra R, Marie Y, Rahimian A, Finocchiaro G, Houlston RS, Hoang-Xuan K, Idbaih A, Delattre JY, Mokhtari K, et al. TERT promoter mutations in 
gliomas, genetic associations and clinico-pathological correlations. British journal of cancer. 2014; 111:2024-2032.

28. Heidenreich B, Nagore E, Rachakonda PS, Garcia-Casado Z, Requena C, Traves V, Becker J, Soufir N, Hemminki K, Kumar R. Telomerase reverse transcriptase promoter mutations in primary cutaneous melanoma. Nature communications. 2014; 5:3401.

29. Killela P, Reitman Z, Jiao YC, McLendon R, Vogelstein B, Bigner D, Diaz L, Yan H. Frequent ATRX, CIC, FUBP1 and IDH1 Mutations Refine the Classification of Malignant Gliomas. J Neuropath Exp Neur. 2013; 72:542-542.

30. Reitman ZJ, Pirozzi CJ, Yan H. Promoting a new brain tumor mutation: TERT promoter mutations in CNS tumors. Acta neuropathologica. 2013; 126:789-792.

31. Nonoguchi N, Ohta T, Oh JE, Kim YH, Kleihues P, Ohgaki H. TERT promoter mutations in primary and secondary glioblastomas. Acta neuropathologica. 2013.

32. Arita H, Narita Y, Takami H, Fukushima S, Matsushita Y, Yoshida A, Miyakita Y, Ohno M, Shibui S, Ichimura K. TERT promoter mutations rather than methylation are the main mechanism for TERT upregulation in adult gliomas. Acta neuropathologica. 2013; 126:939-941.

33. Chen C, Han S, Meng L, Li Z, Zhang X, Wu A. TERT Promoter Mutations Lead to High Transcriptional Activity under Hypoxia and Temozolomide Treatment and Predict Poor Prognosis in Gliomas. PloS one. 2014; 9:e100297.

34. Vinagre J, Almeida A, Populo H, Batista R, Lyra J, Pinto V, Coelho R, Celestino R, Prazeres H, Lima L, Melo M, Rocha AG, Preto A, Castro P, Castro L, Pardal F, et al. Frequency of TERT promoter mutations in human cancers. Nature communications. 2013; 4:2185.

35. Park CK, Lee SH, Kim JY, Kim JE, Kim TM, Lee ST, Choi SH, Park SH, Kim IH. Expression level of hTERT is regulated by somatic mutation and common single nucleotide polymorphism at promoter region in glioblastoma. Oncotarget. 2014; 5:3399-3407.

36. Reifenberger J, Reifenberger G, Liu L, James CD, Wechsler W, Collins VP. Molecular genetic analysis of oligodendroglial tumors shows preferential allelic deletions on $19 q$ and $1 p$. The American journal of pathology. 1994; 145:1175-1190.

37. Killela PJ, Reitman ZJ, Jiao Y, Bettegowda C, Agrawal N, Diaz LA Jr., Friedman AH, Friedman H, Gallia GL, Giovanella BC, Grollman AP, He TC, He Y, Hruban RH, Jallo GI, Mandahl N, et al. TERT promoter mutations occur frequently in gliomas and a subset of tumors derived from cells with low rates of self-renewal. Proceedings of the National Academy of Sciences of the United States of America. 2013; 110:6021-6026.

38. Johnson BE, Mazor T, Hong CB, Barnes M, Aihara K, McLean CY, Fouse SD, Yamamoto S, Ueda $\mathrm{H}$, Tatsuno K, Asthana S, Jalbert LE, Nelson SJ, Bollen AW, Gustafson WC, Charron E, et al. Mutational Analysis
Reveals the Origin and Therapy-Driven Evolution of Recurrent Glioma. Science. 2014; 343:189-193.

39. Labussiere M, Boisselier B, Mokhtari K, Di Stefano AL, Rahimian A, Rossetto M, Ciccarino P, Saulnier O, Paterra R, Marie Y, Finocchiaro G, Sanson M. Combined analysis of TERT, EGFR, and IDH status defines distinct prognostic glioblastoma classes. Neurology. 2014; 83:1200-1206.

40. Simon M, Hosen I, Gousias K, Rachakonda S, Heidenreich B, Gessi M, Schramm J, Hemminki K, Waha A, Kumar R. TERT promoter mutations: a novel independent prognostic factor in primary glioblastomas. Neuro Oncol. 2014.

41. Killela PJ, Reitman ZJ, Jiao YC, Bettegowda C, Agrawal N, Diaz LA, Friedman AH, Friedman H, Gallia GL, Giovanella BC, Grollman AP, He TC, He YP, Hruban RH, Jallo GI, Mandahl N, et al. TERT promoter mutations occur frequently in gliomas and a subset of tumors derived from cells with low rates of self-renewal. Proceedings of the National Academy of Sciences of the United States of America. 2013; 110:6021-6026.

42. Huang FW, Hodis E, Xu MJ, Kryukov GV, Chin L, Garraway LA. Highly recurrent TERT promoter mutations in human melanoma. Science. 2013; 339:957-959.

43. Killela PJ, Reitman ZJ, Jiao Y, Bettegowda C, Agrawal N, Diaz LA Jr., Friedman AH, Friedman H, Gallia GL, Giovanella BC, Grollman AP, He TC, He Y, Hruban RH, Jallo GI, Mandahl N, et al. TERT promoter mutations occur frequently in gliomas and a subset of tumors derived from cells with low rates of self-renewal. Proc Natl Acad Sci U S A. 2013.

44. Liu T, Wang N, Cao J, Sofiadis A, Dinets A, Zedenius J, Larsson C, Xu D. The age- and shorter telomere-dependent TERT promoter mutation in follicular thyroid cell-derived carcinomas. Oncogene. 2014; 33:4978-4984.

45. Xie H, Liu T, Wang N, Bjornhagen V, Hoog A, Larsson C, Lui WO, Xu D. TERT promoter mutations and gene amplification: promoting TERT expression in Merkel cell carcinoma. Oncotarget. 2014; 5:10048-10057.

46. Mason PJ, Perdigones N. Telomere biology and translational research. Translational research : the journal of laboratory and clinical medicine. 2013; 162:333-342.

47. Yu L, Liu S, Zhang C, Zhang B, Simoes BM, Eyre R, Liang Y, Yan H, Wu Z, Guo W, Clarke RB. Enrichment of human osteosarcoma stem cells based on hTERT transcriptional activity. Oncotarget. 2013; 4:2326-2338.

48. Campbell PJ. Telomeres and cancer: from crisis to stability to crisis to stability. Cell. 2012; 148:633-635.

49. Ye D, Ma S, Xiong Y, Guan KL. R-2-hydroxyglutarate as the key effector of IDH mutations promoting oncogenesis. Cancer Cell. 2013; 23:274-276.

50. Zhang C, Moore LM, Li X, Yung WK, Zhang W. IDH1/2 mutations target a key hallmark of cancer by deregulating cellular metabolism in glioma. Neuro Oncol. 2013; 15:1114-1126. 
51. Lotsch D, Ghanim B, Laaber M, Wurm G, Weis S, Lenz S, Webersinke G, Pichler J, Berger W, Spiegl-Kreinecker S. Prognostic significance of telomerase-associated parameters in glioblastoma: effect of patient age. Neuro-Oncology. 2013; 15:423-432.

52. Melin B, Jenkins R. Genetics in glioma: lessons learned from genome-wide association studies. Current opinion in neurology. 2013; 26:688-692.
53. Cawthon RM. Telomere length measurement by a novel monochrome multiplex quantitative PCR method. Nucleic acids research. 2009; 37.

54. Shen M, Cawthon R, Rothman N, Weinstein SJ, Virtamo J, Hosgood HD, Hu W, Lim U, Albanes D, Lan Q. A prospective study of telomere length measured by monochrome multiplex quantitative PCR and risk of lung cancer. Lung Cancer. 2011; 73:133-137. 